CONF-9706 $113^{-}$

AUTHOR(S):

SUEMITED TO:

Chris R. Rose

David B. Barlow

Dale B. Redd

INTIAL TEST RESULTS OF THE LOS ALAMOS

PROTON-STORAGE-RING BUMP-MAGNET SYSTEM
LANSCE-1

LANSCE-1

LANSCE-2

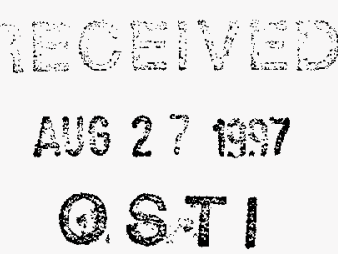

To be presented at the 11th IEEE International Pulsed Power Conference, Baltimore, MD

June 29 - July 2, 1.997
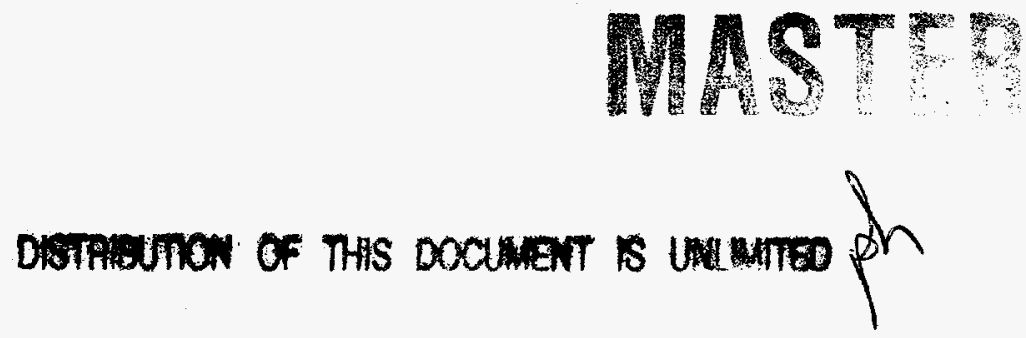

几os

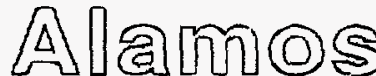

NATIONAL LABORATORY

Los Alamos Natlonal Laboratory, an afilmative action/equal opponunity employer, is operaled by the University of Calliornta for the U.S. Department of Energy under contract W-740S-ENG-36. By acceptance of this article, the publisher recognizes that the U.S. Government retalns a nonexelusive, royalty-tree license to publish or reproduce the published rom of thls contribution, of to allow oiners to do 80 , for U.5, Government purposes. The Los Alambs Nalional Laboratory requests that the publisher idently thls artlele as work pertorned under the euspices of the U.S. Department of Eneigy- 


\section{DISCLAIMER}

This report was prepared as an account of work sponsored by an agency of the United States Government. Neither the United States Government nor any agency thereof, nor any of their employees, make any warranty, express or implied, or assumes any legal liability or responsibility for the accuracy, completeness, or usefulness of any information, apparatus, product, or process disclosed, or represents that its use would not infringe privately owned rights. Reference herein to any specific commercial product, process, or service by trade name, trademark, manufacturer, or otherwise does not necessarily constitute or imply its endorsement, recommendation, or favoring by the United States Government or any agency thereof. The views and opinions of authors expressed herein do not necessarily state or reflect those of the United States Government or any agency thereof. 


\section{DISCLAMIER}

Portions of this document may be illegible in electronic image prodocts. Imsges are produced from the best available original document. 


\title{
INITIAL TEST RESULTS OF THE LOS ALAMOS PROTON-STORAGE-RING BUMP. MAGNET SYSTEM
}

\author{
C. R. Rose, D. B. Barlow, and D. B. Redd \\ Los Alamos National Laboratory \\ PO Box $1663 \mathrm{M} / \mathrm{S} \mathrm{H808}$ \\ Los Alamos, NM 87545
}

\begin{abstract}
An upgrade program for increasing the stored beam current in the LANSCE Proton Storage is presently under way. Part of the upgrade effort has been to design, specify, and add four bump-magnet/modulator systems to the ring. This paper describes the initial test results of the first bump-magnet/modulator system. The paper begins with an overview of the pulsed-power system including important specifications of the modulator, magnet, cabling, and control system. In the main portion of the paper, waveforms and test data are included showing the accuracy, repeatability, and stability of the magnet-current pulses. These magnet pulses are programmable both in rise and fall time as well as in amplitude. The amplitude can be set between 50 and $300 \mathrm{~A}$, the rise-time is fixed at $1 \mathrm{~ms}$, and the linear fall-time can be varicd between $500 \mu \mathrm{s}$ and $1500 \mu \mathrm{s}$. Other issues such as loading effects and power dissipation in the magnet-bore beamtube are examined and reported.
\end{abstract}

\section{Introduction}

The purpose of the bump-magnet modulator system is to "paint" the injected beam into the storage ring. To do this, four bump magnets are used that have precisely controlled, lineardecaying magnetic fields that move the injected beam into the ring synchronously with the ringorbit cycle. The maximum fjeld strength in any one magnet is approximately 500 gauss, and each of the four magnets is pulsed at different field levels with respect to the others. The magnetic field strength of 500 gauss translates roughly to 300 -A peak current in the magnets. A simplified view of one modulator/cable/magnet system is shown below in Fig. 1.

The required current

waveshape is depicted next to the waveform

generator. It has a linear risetime, a flat-top, and a linear decay time. The decay time is variable from 0.5 to

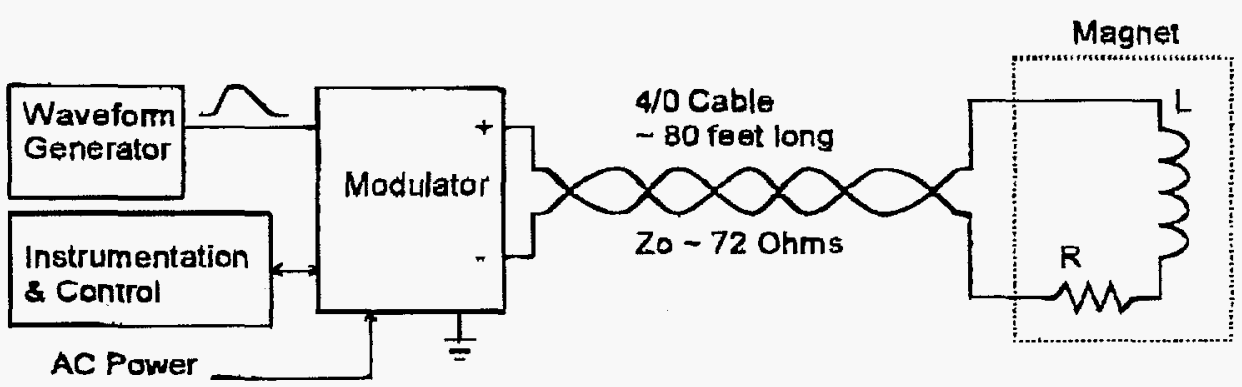

Fig. 1 Block diagram of one bump-magnet system. 
amplitude can be varied from 50 to $300 \mathrm{~A}$. The cable is twisted pair, $4 / 0$ welding cable with a total loop resistance of about $25 \mathrm{~m} \Omega$, and characteristic impedance of $72 \Omega$. The advantage in using welding cable is that it is relatively inexpensive and easy to obtain. Other cable types were considered such as flat low-impedance (in the few Ohm range) strip cables but were much more expensive and didn't allow the use of the present modulator topology.

\section{Bump Magnets}

The four bump magnets are fast-slewing small-deflection dipole magnets. In order to minimize design and prototype development costs, a single magnet design is used for all four magnets. Important magnet parameters are: $30-\mathrm{cm}$ length, $12-\mathrm{cm}$ by $12-\mathrm{cm}$ clear aperture, 16 turns, and $140-\mu \mathrm{H}$ inductance.

Ferrite-yoke magnets were chosen on the basis of their lighter weight, smaller size, and lower overall cost compared to tape-wound-core magnets. A Ceramic Magnetics Inc. MN60 magnetically-soft manganese-zinc ferrite with an initial relative permeability of 6500 , a maximum flux density of $0.45 \mathrm{~T}$, and a coercive force of 0.08 oersteds was chosen for the magnet. At this frequency and flux density, the continuous power loss is less than $1 \mathrm{~mW} / \mathrm{cm}^{3}$. When the duty-cycle (about 3\% for a typical magnet power cycle) is factored in, the average ferrite power loss is negligible. The magnet yoke is made from four ferrite pieces with steps in two of the pieces to lock the pieces together when pressed by an extemal clamping stucture. The magnet windings are single-layer epoxy-potted saddle coils of insulated square copper conductor with a circular internal cooling channel. Resistive power losses in the windings are small enough to be easily removed by air or water cooling.

The largest magnet-related power losses are expected to be in the beam pipe running through the bore of the magnet. Eddy currents in the tube not only cause a power loss but also affect the field within the tube. It is important that the field perturbations be minimized. In the pipe, a characteristic decay time of dipole eddy currents of 15 microseconds or less is allowable. In order to provide a thin-enough wall to minimize the eddy currents and to simultaneously withstand external pressure when the pipe is evacuated, a $0.2 \mathrm{~mm}(0.008$ in.)-wall 316 stainlesssteel formed bellows is used for the beam pipe within the magnet. The duty-cycle averaged eddy-current power for this pipe is estimated to be about 50 watts at $60 \mathrm{~Hz}$ repetition frequency. This amount of power can be removed by natural air convection. The first of the five magnets (four for installation and one backup) has been fabricated by Everson Electric Company and delivered to Los Alamos. The first bump magnet has been field mapped, and the integral field varied less than one percent across the bore of the aperture.

\section{Modulators}

Los Alamos National Laboratory has received one of five-ordered modulators from the vendor, Dynapower Corporation, to be used in the complete bump system. It has been connected to the magnet as shown in Fig. 1 and data taken. In the final system, the peak current of each magnet is independently adjusted while maintaining the same functional shape. In addition, when or if needed (or desired) the waveform of each magnet's current can be slightly adjusted or shaped 
because each modulator will be controlled by a separate programmable-waveform generator. However, in all cases, the timing of all four modulators will be synchronized. The modulators are linear, controlled-current sources which use linearly configured IGBTs to regulate the magnet current. Customary interlocks such as water flow, magnet temperature, and control power on interface to the accelerator control system. The modulator incorporates intemal protection circuitry to protect itself in the event of over-current or overpower dissipation faults. An actual current waveform from the first

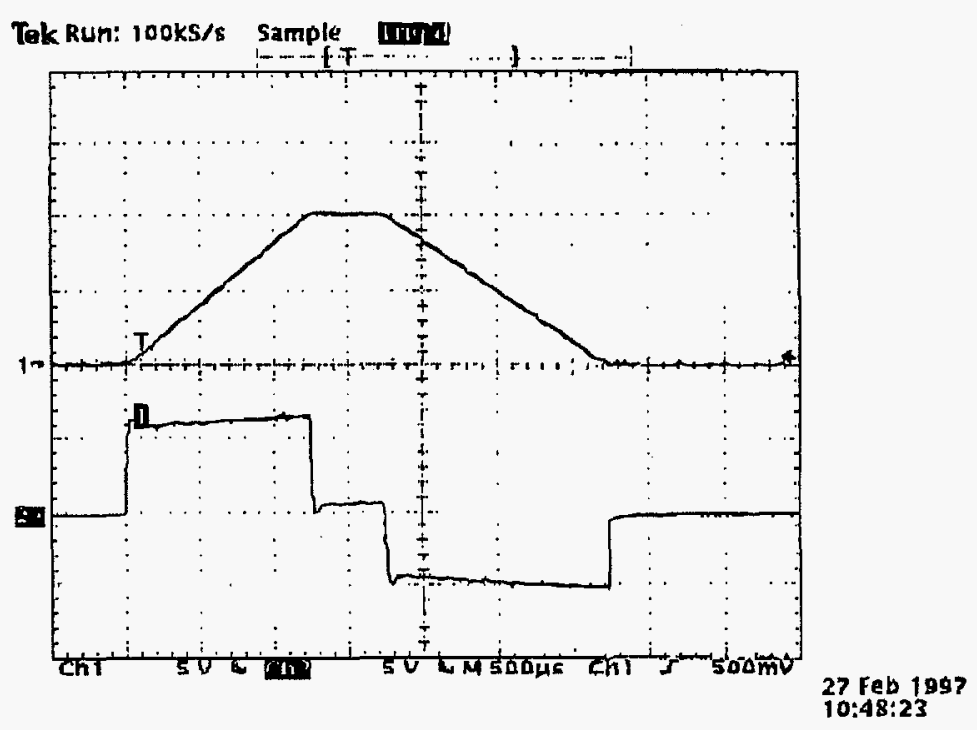

Fig. 2 Waveforms of the magnet current and voltage across the magnet with a $1.5 \mathrm{~ms}$ falltime. Top scale: $30 \mathrm{AN}$, Bottom: $10 \mathrm{VN}$. modulator and magnet pair is shown in Fig. 2.

The top trace is the magnet current, and the bottom is the voltage across the magnet. The leading edge risetime is fixed at about I ms. The ring injection takes place during the downtrending portion of the waveform. It is this portion that must be accurately and repcatedly controlled to ensure accurate and repeatable beam bumping. Each of the four magnets requires different magnetic-field strengths, and different electric-current values. During the leading edge and flat-top. the magnet is energized and brought to the desired current and field level. The flat-top is a holding period used to synchronize the bump system to the ring injection system from which it receives a timing pulse and begins the down ramp.

Data were also taken at other current levels, timing intervals and repetition rates. Fig, 3 shows a 150-A, 60-pps repetition rate pulse with a 1000- $\mu$ s falltime. In the figure, the lower trace shows the voltage across the magnet, and the upper trace is the current in the magnet. Because of $L(d i / d t)$ and

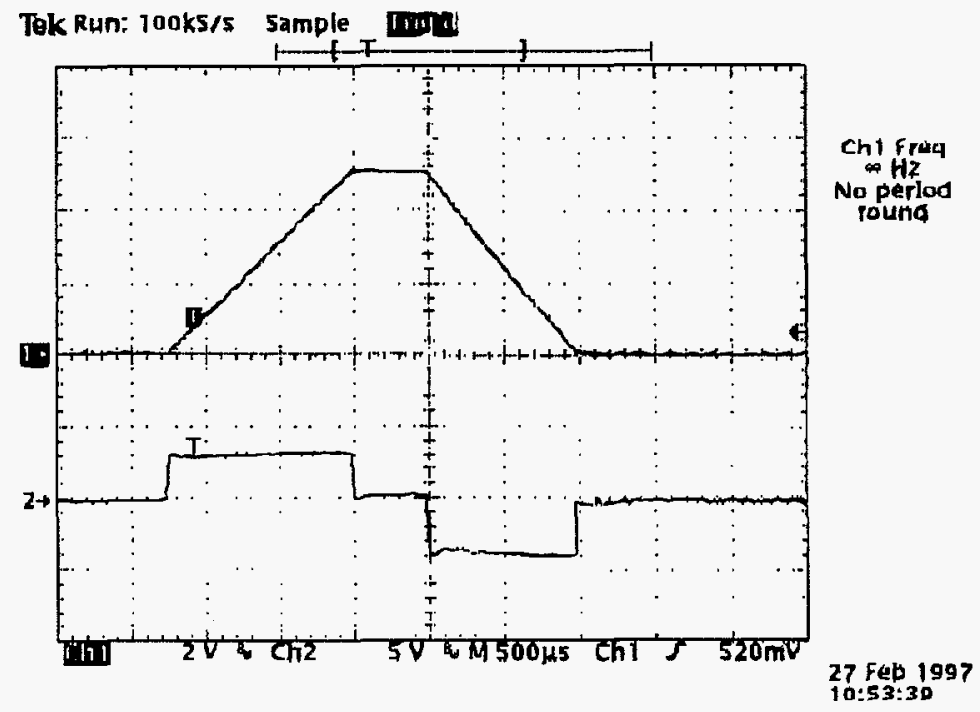

Fig. 3 Waveforms of a full-current (300 A) pulse and the voltage across the magnet. 
resistive losses, the voltage across the magnet ranges from 16 to about $17 \mathrm{~V}$.

In normal operation, a vacuum bellows will be inserted in the bore of the magnet. The integral magnetic field inside the magnet and bellows was measured using a B-dot loop and an OP AMP integrator circuit with a time constant of $5 \mathrm{~ms}$, and a de gain of 1,000 . This waveform, along with several others, is shown in Fig. 4. The top waveform (ch. 1) is from the modulator internal current sensor ( $30 \mathrm{~A} /$ ) and shows a $300-A$ pulse with a $1500 \mu$ s fallitine.

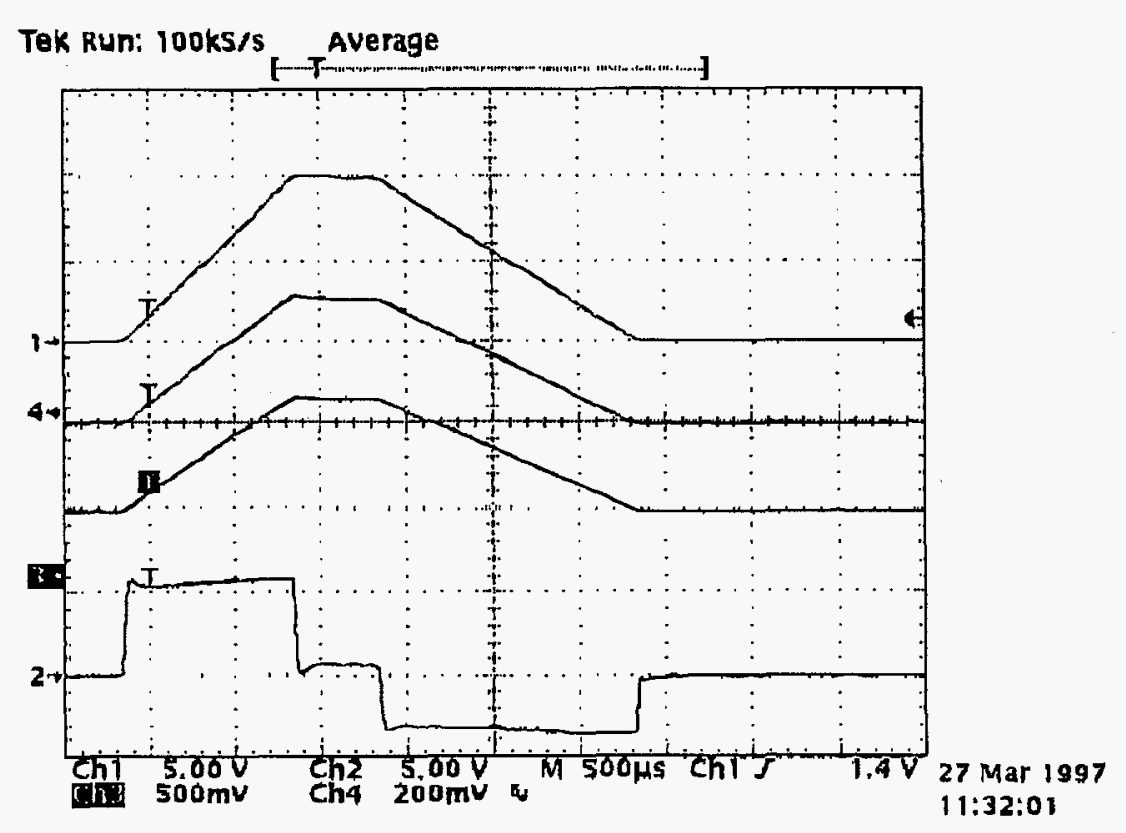

Fig. 4 Measured waveforms of a 300-A pulse. Channel 2 is the voltage actoss the magnet at $10 \mathrm{~V} / \mathrm{V}$. Channel 3, the highlighted indicator, is from the integrator. Channel 4 is from a Pearson 30250.001 V/A curtent transformer. These waveforms were taken with the bellows inside the bore of the magnet.

The accuracy of the current waveform with respect to the programming signal was measured and found to be less than one percent at the comers which is twice as good as the specified accuracy, and less than 0.2 percent during the smooth parts of the function.

\section{Conclusions}

At present, there is one operating bump system at Los Alamos from which data has been taken. The first magnet and modulator have been connected together and operated at full current and full repetition rate of $60 \mathrm{~Hz}$. The remaining magnets and modulators are presently on order from the respective vendors and are scheduled for installation during the Fall of 1997. 